\title{
Algunos aspectos etiológicos y epidemiológicos del sindrome diarreico agudo infantil ${ }^{*}$
}

DR. GERMAN COREY, **

\section{INTRODUCCION}

La diarrea aguda infantil es responsable en los últimos años en nuestro país de un $5-6 \%$ del total de consultas anuales. Esta proporción aumenta significativamente hacia los grupos de edades menores. Además, la diarrea aguda es responsable de un 25$30 \%$ de los egresos hospitalarios pediátricos en periodos estivales. Finalmente, durante los últimos años aproximadamente el 17\% de las tasas de mortalidad infantil se deben a esta causa.

Variadas investigaciones efectuadas han demostrado ampliamente la influencia de diversos factores condicionantes, que en mayor o menor grado inciden en la prevalencia de la diarrea aguda en los niños. Entre ellos se han considerado tradicionalmente la calidad sanitaria del medio ambiente, el nivel cultural y socioeconómico de las familias afectadas, el estado nutricional del niño enfermo y oportunidad y calidad de la atención médica.

Pareció por lo tanto de interés plantear un estudio que combinara algunos elementos clínico-terapéuticos, epidemiológicos y etiológicos del síndrome diarreico agudo en niños, que permitiera conocer la situación en un período estival determinado en la ciudad de Santiago.

\section{PROPOSITOS Y OBJETIVOS}

Propósito de éste ha sido contribuir al mejor conocimiento epidemiológico, clínico

\footnotetext{
(*) Tesis, en calidad de Becado en Salud Pública (SNS). Su realización contó con la valiosa participación y colaboración del Dcpartamento de Micmbiologia y Parasitología de la Facultad de Medicina de la Universidad de Chile y dó Instituto Bacteriológico de Chile.

(**) Médico Ayudante de la Sección Epidemiología de la Dirección General del SNS.
}

y de comportamiento terapéutico de las diarreas agudas en la población infantil menor de 6 años. Para ello se precisaron los siguientes objetivos:

1.- Conocer la prevalencia bacteriana, viral y parasitaria en los cuadros diarreicos agudos estivales de niños menores de 6 años.

2.- Conocer la prevalencia bacteriana, viral y parasitaria en período estival en niños sanos menores de 6 años.

3.- Conocer la efectividad de los tratamientos habituales según normas (1) sobre la evolución clínica del síndrome diarreico agudo de diferentes etiologías.

4.- Conocer las interacciones entre los enterovirus citopatógenos y los enterovirus polio atenuados en relación con la incidencia del síndrome diarreico agudo en los niños menores de 6 años.

5.- Conocer las relaciones de interés epidemiológico entre el rubro "etiología microbiana de la diarrea" y variables tales como cuadro clínico, estado nutritivo del enfermo y características sanitarias del habitat de éste.

Material y MÉtodo. 1. La población estudiada fueron niños entre 0 y 5 años 11 meses de edad, consultantes entre enero y marzo de 1973, en cuatro consultorios urbanos de Santiago (2).

(1) Los criterios clínicos y terapéuticos en las actividades de este rubro se ciñen a las "Normas de Prevención, Tratamiento y Control de las Diarreas Infantiles" del SNS, ediladas en 1972. Hace excepción en ella el uso de la furazolidona.

(2) Consultorios: La Pincoya, del Arca Norte; No 1 del Area Central; San Joaquín, del Arca Sur y Bellavista, del Area Sur Oriente. 
2. La población infantil se dividió en tres grupos: Niños de 0 a 5 años 11 meses, que consultaron espontáneamente por diarrea aguda. Los niños de este grupo equivalen a una muestra seleccionada ya que requisitos para ingresar al estudio fueron que el cuadro diarreico no tuviera más de 72 horas de evolución y sin tratamiento antibiótico previo (3).

Niños sanos de 0 a 5 años 11 meses seleccionados al azar a partir de niños que concurrieron a control de salud, que no habían tenido cuadros infecciosos respiratorios ni diarrea en los 15 días inmediatamente precedentes.

Niños sanos o enfermos de 0 a 5 años 11 meses, convivientes y contactos de los niños enfermos del primer grupo.

3. En cada niño del primer grupo se registraron los antecedentes respecto del cuadro clínico, el estado nutritivo, el antecedente de vacuna antipoliomielítica oral y las condiciones de su habitat, tomándosele luego muestras de deposiciones para estudio microbiológico, de acuerdo al siguiente modo: una muestra para estudio bacteriológico al momento de primera consulta, dos muestras para el estudio virológico, con 4-6 días de intervalo, y tres muestras para estudio parasitológico tomadas día por medio (4).

A los niños enfermos se les tomó además dos muestras pareadas de sangre separadas por 2 a 3 semanas para el estudio serológico de virus, situación que debió considerar la presencia o no de algún otro cuadro diarreico entre la toma de ambas.

4. La atención de los enfermos fue hecha siempre por dos mismos médicos, quienes efectuaron la anamnesis, el examen físico y el diagnóstico en cada caso, consignaron los antecedentes y procedieron a tomar las muestras de deposiciones. Procedieron también a indicar el tratamiento correspondiente según normas y a citar a control para 3-4 días después para evaluar evolución clínico-terapéutica y completar antecedentes.

5. A los niños sanos en control de salud se les consignó los antecedentes y se procedió a tomar muestras de deposiciones según igual esquema especificado para los enfer-

(3) Pudo haber recibido antibiótico hasta 24 horas antes.

(4) Las muestras de deposiciones para bacterias y virus se hicieron mediante hisopo rectal, siendo luego trasladadas a los laboratorios correspondientes en donde se iniciaba su procesamiento antes de 6 horas desde su toma. I as muestras del parasitológico se tomaron del pañal. mos. El criterio de permanencia de estos niños en el estudio consideró el que continuasen sanos desde el punto de vista de ausencia de diarrea durante los 4 días siguientes a la toma de la última muestra de deposiciones.

Resultados. Dados los diversos requitos establecidos, durante los meses de enero a marzo de 1973 se logró introducir con antecedentes completos al estudio sólo a 178 niños entre 0 a 5 años de edad. Corresponden a 88 niños con diarrea aguda, 50 niños sanos a modo de grupo control y 40 niños contactos de los enfermos con diarrea. Se logró efectuar control clínico terapéutico a 78 de los 88 niños enfermos.

En todos ellos se efectuó el número programado de exámenes coprológicos, con la sola excepción de las muestras parasitológicas que en promedio se efectuaron 2,5 exámenes por niño. Sólo se logró completar en 62 enfermos las dos muestras pareadas de sangre.

A continuación se exponen los resultados de más interés obtenidos en cada grupo. Respecto del grupo con diarrea, los antecedentes se exponen para los 88 niños en primera consulta, pero en la evolución clínica y control terapéutico se hace sólo para los 78 niños que volvieron a control.

Entre enfermos y sanos se observa una distribución sin diferencias significativas de algunas variables tales como distribución por grupos de edad, grado de prematuridad, control de salud, nivel educacional materno, estado nutritivo previo, antecedentes de síntomas sospechosos de enteroparasitosis, suministro de agua potable, tipo de disposición de excretas y grado de hacinamiento. Cabe destacar, no obstante, algunos hechos: el $8-9 \%$ de prematuridad es algo menor que las cifras nacionales promedios, el grado de analfabetismo materno es del orden del 9$10 \%$, la desnutrición previa se pesquisó en un $32 \%$ globalmente para ambos grupos.

Sin embargo, se encontraron diferencias estadísticamente significativas entre ambos grupos en los siguientes aspectos: episodios diarreicos agudos en los dos meses anteriores, presencia de otro enfermo con diarrea en el hogar, número de personas por cama $y$ presencia de vectores, fundamentalmente moscas, en hogar. El grupo de niños con diarrea presentó los índices más desfavorables en estos cuatro aspectos.

Con poca frecuencia se encontró el antecedente de cambio reciente en la dieta o de introducción de algún nuevo alimento. 


\begin{tabular}{|c|c|c|c|c|c|}
\hline Antecedentes & & \multicolumn{2}{|c|}{$\begin{array}{l}\text { Niños con diarnea } \\
\text { aguda }\end{array}$} & \multicolumn{2}{|c|}{ Niños sanos } \\
\hline \multirow[t]{3}{*}{ Edad } & $0-11$ meses & 50 & 56,7 & 26 & 52,0 \\
\hline & 1 año & 23 & 26,2 & 14 & 28,0 \\
\hline & 2 - 5 años & 15 & 17,1 & 10 & 20,0 \\
\hline \multirow[t]{2}{*}{ Peso nacimiento } & $-2.500 \mathrm{~g}$ & 8 & 9,1 & 4 & 8,0 \\
\hline & 2500 g y más & 80 & 90,9 & 46 & 92,0 \\
\hline \multirow[t]{2}{*}{ Control de salud } & No & 5 & 5,7 & 0 & 0,0 \\
\hline & regular & 83 & 94,3 & 50 & 100,0 \\
\hline \multirow{3}{*}{$\begin{array}{l}\text { Educación } \\
\text { materna }\end{array}$} & analfabeta & 8 & 9,0 & 5 & 10,0 \\
\hline & básica & 63 & 71,5 & 36 & 72,0 \\
\hline & media & 17 & 19,5 & 9 & 18,0 \\
\hline \multirow[t]{2}{*}{ Estado nutritivo } & eutrofia & 62 & 70,5 & 31 & 62,0 \\
\hline & desnutrición (1) & 26 & 29,5 & 19 & 38,0 \\
\hline \multirow{2}{*}{$\begin{array}{l}\text { Diarrea en últimos } \\
\text { dos meses }\end{array}$} & Sí & 34 & 38,6 & 4 & 8,0 \\
\hline & No & 54 & 61,4 & 46 & 92,0 \\
\hline \multirow{2}{*}{$\begin{array}{l}\text { Otro enfermo con } \\
\text { diarrea en hogar }\end{array}$} & Sí & 16 & 18,2 & 1 & 2,0 \\
\hline & No & 72 & 81,8 & 49 & 98,0 \\
\hline \multirow{2}{*}{$\begin{array}{l}\text { Síntomas de ente- } \\
\text { roparasitosis }\end{array}$} & Sí & 29 & 32,9 & 11 & 22,0 \\
\hline & No & 59 & 67,1 & 39 & 78,0 \\
\hline \multirow[t]{2}{*}{ Aguda potable } & en casa & 54 & 61,3 & 38 & 76,0 \\
\hline & de acarreo & 34 & 38,7 & 12 & 24,0 \\
\hline \multirow{2}{*}{$\begin{array}{l}\text { Disposición de } \\
\text { excretas }\end{array}$} & adecuada & 40 & 45,4 & 24 & 48,0 \\
\hline & inadecuada & 48 & 54,6 & 26 & 52,0 \\
\hline \multirow{2}{*}{$\begin{array}{l}\text { Presencia de } \\
\text { vectores }\end{array}$} & Sí & 73 & 82,9 & 27 & 54,0 \\
\hline & No & 15 & 17,1 & 23 & 46,0 \\
\hline Personas por & $1-2$ & 64 & 72,7 & 41 & 82,0 \\
\hline pieza & 3 y más & 24 & 27,3 & 9 & 18,0 \\
\hline Personas por & 1 & 26 & 29,5 & 35 & 70,0 \\
\hline cama & 2 y más & 62 & 71,5 & 15 & 30,0 \\
\hline
\end{tabular}

(1) Incluye desnutrición en primer grado en su gran proporción y desnutrición en segundo grado en la menor parte. No se pesquisaron casos de 3er. grado.

Cerca de un $40 \%$ de los niños presentaba un cuadro mórbido concomitante con la diarrea. Los diagnósticos más frecuentes en orden de prioridad fueron faringitis aguda, bronquitis aguda, erupción dentaria y resfrío común.

Los resultados en cuanto a horas de evolución de la diarrea y a tratamiento previo, coinciden en gran medida con las exigencias en la selección de los niños.

En relación a características de la diarrea misma, se observó una frecuencia predominante de 1 a 6 deposiciones por día, preferentemente disgregada y preferentemente sin mucosidades ni sangre.

En cuanto al tipo de diarrea, destaca un predominio de la diarrea aguda sin deshidratación; la diarrea aguda con deshidratación fue $3,3 \%$. Esto está en relación con las pocas horas de evolución que se exigía a los niños.

La frecuencia de vómitos fue baja, afectando sólo a un tercio de los consultantes, así como también la gran mayoría de los niños $(85,2 \%)$ no presentó fiebre al momento de la consulta o la presentó en nivel muy bajo.

Los niños con diarrea muestran un aumento de la desnutrición con la edad. Además, destaca que en éstos la proporción de niños desnutridos es más alta en las madres analfabetas, viéndose un descenso marcado hacia la madre con educación media. Esta variación no es tan acentuada en los niños sanos. 


\begin{tabular}{llrr}
\hline \multicolumn{1}{c}{ Características } & & No & $\%$ \\
\hline Cambio reciente en la dicta & sí & 4 & 4,6 \\
Introducción de nuevo alimento & no & 84 & 95,4 \\
Cuadro mórbido concomitante & sí & 18 & 20,3 \\
& no & 70 & 79,7 \\
Horas de cvolución de la diarrea & sí & 33 & 37,5 \\
& no & 55 & 62,5 \\
Tratamiento previo & -24 horas & 39 & 44,2 \\
& $25-48$ horas & 24 & 27,2 \\
Número de deposiciones diarias & 49 y más & 25 & 28,6 \\
& Sin & 37 & 42,0 \\
Aspecto de las deposiciones & Dieta hídrica & 42 & 47,7 \\
& Antibióticos & 9 & 10,3 \\
& $1-6$ & 70 & 79,4 \\
Tipo de diarrea & 7 y más & 18 & 20,6 \\
& Líquida & 23 & 26,1 \\
Vómitos & Disgregada & 65 & 73,9 \\
Temperatura & Con mucus y/o sangre & 35 & 39,8 \\
& sin mucus ni sangre & 53 & 60,2 \\
& Simple & 6 & 6,8 \\
& sin deshidratación & 79 & 89,8 \\
& con deshidratación & 3 & 3,3 \\
& Sí & 33 & 37,5 \\
& No & 55 & 62,5 \\
& Afebril & 39 & 44,3 \\
& $37,5-38,0$ & 36 & 40,9 \\
& $38,1-40,1$ & 13 & 14,8 \\
\hline
\end{tabular}

En ambos grupos se ve una concentración significativamente mayor de desnutridos entre los que acusaban algún episodio diarreico dentro de los 2 meses previos y entre los que hay un enfermo con diarrea en el hogar.

Tanto en enfermos como sanos hay mayor acúmulo de desnutridos en los grupos con disposición inadecuada de excretas, con agua potable de acarreo y con altos niveles de hacinamiento y promiscuidad.

El grupo con diarrea presenta desnutridos en una proporción significativamente mayor cuando se declara presencia de vectores que cuando no los hay.

En general se observa un alto grado de mejoría de los niños al 4\% día de control clínico, del orden de un $83,3 \%$. Y es altamente llamativo ver que no hay diferencia significativa alguna en la mejoría según se modifiquen las distintas variables consideradas, $\mathrm{ni}$ siquiera el estado nutritivo.

El grupo diarrea y el grupo sano comparables en edades, presentan proporción de coprocultivos negativos sensiblemente igual entre ellos. Dicho de otro modo, en casos de diarrea se aisla algún germen en un $56,8 \%$ y en sanos se aisla algún germen en un $46 \%$, valores que no presentan diferencia significativa. El grupo de contactos, no comparable en edad con los otros, presenta una proporción mayor de positividad debido a que gran parte de ellos son preescolares con alta tasa de infección con enteroparásitos.

El grado de aislamiento de enterobacterias como único agente infeccioso es igual para los 3 grupos. En cambio el aislamiento de enterovirus es significativamente más alto en el grupo diarrea que en los otros dos.

Se muestra, independientemente del aislamiento de uno o más gérmenes, la prevalencia encontrada según tipo de gérmenes y según edades.

Las diferencias observadas en las cifras no son estadísticamente significativas, sin embargo destaca el aislamiento de bacterias, virus y parásitos en proporciones semejantes tanto en niños con diarrea como en niños sanos, aún cuando en virus se observa una tendencia a aislarlos más frecuentemen- 


\begin{tabular}{|c|c|c|c|c|c|c|c|}
\hline \multirow[t]{2}{*}{ Antecedentes } & & \multicolumn{3}{|c|}{$\begin{array}{c}\text { Grupo diarrea } \\
\text { Total Desnutridos }\end{array}$} & \multicolumn{3}{|c|}{$\begin{array}{l}\text { Grupo sano control } \\
\text { Total Desnutridos }\end{array}$} \\
\hline & & niños & $N^{o}$ & $\%$ & niños & $N^{o}$ & $\%$ \\
\hline \multirow[t]{4}{*}{ Edades } & 0 - 11 meses & 50 & 11 & 22,0 & 26 & 9 & 34,6 \\
\hline & 12.23 meses & 23 & 8 & 34,8 & 14 & 8 & 57,1 \\
\hline & 2 - 5 años & 15 & 7 & 46,6 & 10 & 2 & 20,0 \\
\hline & Total 0 - 5 años & 88 & 26 & 29,5 & 50 & 19 & 38,0 \\
\hline \multirow{2}{*}{ Peso nacimiento } & -2.500 grs. & 8 & 3 & 37,5 & 4 & 3 & 75,0 \\
\hline & 2.500 grs. y más & 80 & 23 & 28,7 & 46 & 16 & 34,8 \\
\hline \multirow{3}{*}{$\begin{array}{l}\text { Nivel educacional } \\
\text { materno }\end{array}$} & analfabeta & 8 & 6 & 75,0 & 5 & 3 & 60,0 \\
\hline & educación básica & 63 & 18 & 28,6 & 36 & 12 & 33,0 \\
\hline & educación media & 17 & 2 & 11,8 & 9 & 4 & 44,0 \\
\hline \multirow{2}{*}{$\begin{array}{l}\text { Diarrea en últimos } \\
\text { dos meses }\end{array}$} & Sí & 34 & 13 & 38,2 & 4 & 3 & 75,0 \\
\hline & No & 54 & 13 & 24,0 & 46 & 16 & 34,8 \\
\hline \multirow{2}{*}{$\begin{array}{l}\text { Otro enfermo con } \\
\text { diarrea en hogar }\end{array}$} & Sí & 16 & 6 & 37,5 & 1 & 1 & 100,0 \\
\hline & No & 72 & 20 & 27,8 & 49 & 18 & 36,7 \\
\hline \multirow{2}{*}{$\begin{array}{l}\text { Disposición de } \\
\text { excretas }\end{array}$} & Adecuada & 40 & 8 & 20,0 & 24 & 9 & 37,5 \\
\hline & inadecuada & 48 & 18 & 37,5 & 26 & 10 & 38,5 \\
\hline \multirow[t]{2}{*}{ Agua potable } & En casa & 54 & 13 & 24,0 & 38 & 13 & 34,2 \\
\hline & acarreo & 34 & 13 & 38,2 & 12 & 6 & 50,0 \\
\hline \multirow{2}{*}{$\begin{array}{l}\text { Personas por } \\
\text { pieza }\end{array}$} & $1-2$ & 64 & 16 & 25,0 & 41 & 12 & 30,0 \\
\hline & 3 y más & 24 & 10 & 45,5 & 9 & 7 & 77,7 \\
\hline \multirow{2}{*}{$\begin{array}{l}\text { Personas por } \\
\text { cama }\end{array}$} & 1 & 26 & 6 & 23,0 & 35 & 11 & 31,4 \\
\hline & 2 y más & 62 & 20 & 32,0 & 15 & 8 & 53,3 \\
\hline \multirow[t]{2}{*}{ Vectores } & Sí & 73 & 24 & 32,9 & 27 & 11 & 40,7 \\
\hline & No & 15 & 2 & 13,3 & 23 & 8 & 34,8 \\
\hline
\end{tabular}

te en el grupo con diarrea, tanto globalmente como por grupos de edades.

El aislamiento de bacterias no varía según varíen las edades; el virus tiende a ser discretamente mayor a medida que el niño es mayor en edad y el de parásitos muestra una alta prevalencia hacia los preescolares.

Entre las bacterias predomina la escherichia coli enteropatógena, en diversos fagotipos, siendo más frecuente la 055. Salmonellas y shigellas se aislaron en grado mínimo.

Entre los virus se aisló una proporción importante de virus Echo y de coxsackie B.

Entre los parásitos se aisló con gran frecuencia giardia lamblia. Entoameba histolítica sólo se encontró en 3 casos.

La distribución de las bacterias es homogénea entre sanos y enfermos, con excepción de la ECEP 055 que se aisló significativamente más en los niños con diarrea. Los virus Echo y la giardia lamblia se aislaron más frecuentemente en el grupo enfermo y sus contactos que en los sanos.

Se presenta el grado de positividad del coprocultivo a cualquier germen en niños con diarrea y en sanos.

En general no se aprecian diferencias substanciales entre ambos grupos en la positividad del coprocultivo según las variables analizadas. Sin embargo, se puede destacar algunos hechos.

Todos los niños tienden a tener más gérmenes a medida que suben en edad.

A medida que el nivel educacional materno sube, la presencia de gérmenes es mayor. Las diferencias entre los extremos de las gradientes no son significativas.

El niño que ha tenido diarrea en los últimos dos meses tiende a tener mayor positividad en el coprocultivo, pero las diferencias no son significativas con el grupo opuesto, tanto en enfermos como sanos.

En el grupo de niños con diarrea se constató una diferencia significativa en la positividad del examen de aquéllos con antecedentes de diarrea en el grupo familiar contra los que informaron negativamente. Cosa semejante se observa para el antecedente de grado de promiscuidad. 


\section{RELACION ENTRE ANTECEDENTES DE NIÑOS ENFERMOS CON LA EVOLUCION CLINICA (1).}

\begin{tabular}{|c|c|c|c|c|}
\hline \multirow[t]{2}{*}{ Antecedentes } & & \multirow[b]{2}{*}{ Total } & \multicolumn{2}{|c|}{$\begin{array}{c}\text { Mejoral al controt } \\
\text { del } 4^{a} \text { dia }\end{array}$} \\
\hline & & & $N^{a}$ & $\%$ \\
\hline \multirow[t]{5}{*}{ Edades } & $0-5$ meses & 26 & 22 & 84,6 \\
\hline & $6-11$ meses & 17 & 12 & 70,5 \\
\hline & $12-23$ meses & 21 & 18 & 85,7 \\
\hline & 2 - 5 años & 14 & 13 & 92,8 \\
\hline & total $0-5$ años & 78 & 65 & 83,3 \\
\hline \multirow[t]{3}{*}{ Educación materna } & analfabeta & 8 & 8 & 100,0 \\
\hline & educación básica & 55 & 42 & 76,4 \\
\hline & educación media & 15 & 15 & 100,0 \\
\hline \multirow{2}{*}{$\begin{array}{l}\text { Diarrea en últimos } \\
\text { dos meses }\end{array}$} & sí & 32 & 24 & 75,0 \\
\hline & no & 46 & 41 & 89,1 \\
\hline \multirow{2}{*}{$\begin{array}{l}\text { Otro enfermo con } \\
\text { diarrea en hogar }\end{array}$} & sí & 26 & 23 & 88,5 \\
\hline & no & 52 & 42 & 80,8 \\
\hline \multirow{2}{*}{$\begin{array}{l}\text { Disposición de } \\
\text { excretas }\end{array}$} & adecuada & 38 & 31 & 81,6 \\
\hline & inadecuada & 40 & 34 & 85,0 \\
\hline \multirow{2}{*}{ Agua potable } & en casa & 48 & 41 & 85,4 \\
\hline & de acarreo & 30 & 24 & 80,0 \\
\hline \multirow{2}{*}{$\begin{array}{l}\text { Persanas por } \\
\text { pieza }\end{array}$} & $1-2$ & 55 & 47 & 85,4 \\
\hline & 3 y más & 23 & 18 & 78,2 \\
\hline \multirow{2}{*}{$\begin{array}{l}\text { Personas por } \\
\text { cama }\end{array}$} & 1 & 25 & 19 & 76,0 \\
\hline & 2 y más & 53 & 46 & 86,7 \\
\hline \multirow[t]{2}{*}{ Vectores } & sí & 60 & 51 & 85,0 \\
\hline & no & 18 & 14 & 77,7 \\
\hline \multirow{2}{*}{$\begin{array}{l}\text { Cuadro mórbido } \\
\text { concomitante }\end{array}$} & sí & 28 & 25 & 89,2 \\
\hline & no & 50 & 40 & 80,0 \\
\hline \multirow{5}{*}{$\begin{array}{l}\text { Características del } \\
\text { coprocultivo }\end{array}$} & negativo & 28 & 24 & 85,6 \\
\hline & sólo con bacterias & 11 & 10 & 90,9 \\
\hline & sólo con virus & 10 & 8 & 80,0 \\
\hline & sólo con parásitos & 13 & 10 & 75,3 \\
\hline & polimicrobiano & 16 & 14 & 87,5 \\
\hline \multirow[t]{2}{*}{ Estado nutritivo } & eutríficos & 55 & 46 & 83,6 \\
\hline & desnutridos & 23 & 19 & 82,6 \\
\hline
\end{tabular}

(1) De los 88 niños con diarrea, la evolución clínica se efectuó en 73 que vuelven a control. Los 10 niños restantes ( 3 de los cuales, con deshidratación, habian sido enviados a hospita lizar), fueron posteriormente visitados en sus hogares en dondc se constató la recuperación del estado diarreico y la ausen cia de fallecidos.

$$
\text { T A B L A } 5
$$

POSITIVIDAD DEL COPROCULTIVO EN GRUPOS ESTUDIADOS SEGUN TIPO DE GERMEN ENTERICO

\begin{tabular}{lcccrcr}
\hline Caracteristicas del coprocuttivo & \multicolumn{3}{c}{ Grupo diarrea } & \multicolumn{2}{c}{ Grupo sano } & \multicolumn{2}{c}{ Grupo contactos } \\
& No & $\%$ & $N^{o}$ & $\%$ & $N^{o}$ \\
\hline Sin aislamiento microbiano & 38 & 43,2 & 27 & 54,0 & 8 & 20,0 \\
Sólo con enterobacterias & 11 & 12,5 & 6 & 12,0 & 4 & 10,0 \\
Sólo con enterovirus & 10 & 11,3 & 3 & 6,0 & 1 & 2,5 \\
Sólo con enteroparásitos & 13 & 14,7 & 7 & 14,0 & 18 & 45,0 \\
Can resultados polimicrobianos & 16 & 18,3 & 7 & 14,0 & 9 & 22,5 \\
\hline T o t a l & 88 & 100,0 & 50 & 100,0 & 40 & 100,0 \\
\hline
\end{tabular}


T A B L A 6

TIPO DE GERMENES ENTERICOS AISLADOS SEGUN EDADES EN LOS GRUPOS ESTUDIADOS

\begin{tabular}{|c|c|c|c|c|c|c|c|c|c|c|c|c|c|c|c|c|c|c|c|c|c|}
\hline \multirow[b]{3}{*}{ Edades } & \multicolumn{5}{|c|}{ GRUPO DIARREA } & \multicolumn{9}{|c|}{ GRUPO SANO } & \multicolumn{7}{|c|}{ GRUPO CONTACTOS } \\
\hline & Total & Bact & erlas & Vir & us (1) & Par & Sisitos & Total & Bac & erlas & & rus & Par & iltos & Total & Bac & erias & V1 & rus & Parris & ftos \\
\hline & niños & № & $\%$ & No & $\%$ & No & $\%$ & niños & No & $\%$ & No & $\%$ & № & $\%$ & niños & № & $\%$ & No & $\%$ & № & $\%$ \\
\hline & 50 & 13 & 26,0 & 10 & & 8 & & 26 & 7 & & 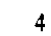 & & & & & & & 0 & 0,0 & 0 & 0,0 \\
\hline $1 \mathrm{a}$ & 23 & 7 & 30,4 & 6 & 26,0 & 9 & 39,0 & 14 & 4 & 28,5 & 2 & 14,3 & 3 & 21,4 & 1 & 0 & 0,0 & 1 & 100,0 & 0 & 0,0 \\
\hline 2 - 5 años & 15 & 4 & 26,6 & 4 & 26,8 & 11 & 73 & 10 & 3 & 30,0 & 2 & 20,0 & 6 & 60,0 & 35 & 9 & 25,7 & 7 & 20,0 & 26 & 76,2 \\
\hline TOTAL (2) & 88 & 24 & 27,8 & 20 & 22,9 & 28 & 31,8 & 50 & 14 & 28,0 & 8 & 16,0 & 11 & 22,0 & 40 & 9 & 22,5 & 8 & 20,0 & 26 & 65,0 \\
\hline
\end{tabular}

(1) Se omiten 2 casos en que se aisló virus polio 2. probablemente vaccinales, y en los que la vacuna Sabin fue administra. da entre 2 y 60 días antes de la toma de la mucstra.

(2) Se aisló, conjuntamente entre enfermos y sanos, control (138 niños), un $27,5 \%$ de bacterias $(24+14)$, un $21 \%$ de virus $(20+8)$ y un $27,7 \%$ de parásitos $(28+11)$.

T A B L A 7

FRECUENCIA DE GERMENES AISLADOS DE NIÑOS CON DIARREA, NIÑOS SANOS Y CONTACTOS (1)

\begin{tabular}{llcccr}
\hline Gérmenes entéricos & & $\begin{array}{c}\text { Grupo } \\
\text { Dlarrea }\end{array}$ & $\begin{array}{c}\text { Grupo } \\
\text { Sano }\end{array}$ & $\begin{array}{c}\text { Grupo } \\
\text { Contacto }\end{array}$ & Total \\
\hline \multirow{4}{*}{ bacterias } & escherichia coli 055 & 10 & 3 & 3 & 16 \\
& escherichia coli 026 & 3 & 2 & 0 & 5 \\
& escherichia coli 086 & $2(25 \%)$ & $2(26 \%)$ & $1(20 \%)$ & 5 \\
& escherichia coli 0128 & 3 & 1 & 1 & 5 \\
& escherichia coli otros & 4 & 5 & 3 & 12 \\
& salmonella & 1 & 1 & 0 & 2 \\
\hline \multirow{4}{*}{ virus } & shigella & 1 & 0 & 1 & 2 \\
& Echo (6, 7, 11 y 19) & 6 & 1 & 3 & 10 \\
& coxsackie A & 3 & 2 & 0 & 5 \\
& coxsackie B (3 y 5) & 3 & 2 & 4 & 9 \\
polio 2 & 2 & 0 & 0 & 2 \\
parásitos & herpes simplex & 2 & 0 & 1 & 10 \\
\hline & no tipificable & 6 & 3 & $21(53 \%)$ & 57 \\
& giardia lamblia & $26(30 \%)$ & $10(20 \%)$ & 19 & 30 \\
& H. Nana & 8 & 3 & 1 & 3 \\
\hline
\end{tabular}

(1) Los $\%$ entre paréntesis se refieren sobre el total de niños

Se correlaciona el grado de positividad del coprocultivo a cualquier germen con el cuadro clínico y con la evolución de éste al 4! día.

No existe variación significativa en la positividad del coprocultivo con respecto de las variables expuestas.

La distribución relativa de los diversos gérmenes, no expuesta aquí, igualmente no presenta variaciones significativas. Sin embargo, al confrontar algunos antecedentes de ambos grupos con el grado de aislamiento de los tres tipos de gérmenes estudiados podemos destacar los siguientes hechos.
No se observa diferencias en el aislamiento de los gérmenes según se modifiquen el nivel educacional materno, la disponibilidad de agua potable, la disposición de excretas, la presencia de vectores y el grado de hacinamiento.

Se encontró un mayor aislamiento de enteroparásitos en los niños desnutridos que en los eutróficos.

Se aisló, tanto bacterias como virus y parásitos, en grado significativamente mayor en los niños enfermos con antecedentes de diarrea en el grupo familiar que en aquéllos con antecedentes negativos. 


\begin{tabular}{|c|c|c|c|c|c|c|c|}
\hline \multirow[t]{2}{*}{ Antecedentes } & & \multicolumn{3}{|c|}{$\begin{array}{c}\text { Grupo diarrea } \\
\text { Total Coprocultivo }(+)\end{array}$} & \multicolumn{3}{|c|}{$\begin{array}{c}\text { Grupo sano } \\
\text { Total Coprocultivo' }(+)\end{array}$} \\
\hline & & niños & $N^{o}$ & $\%$ & niños & $N^{o}$ & $\%$ \\
\hline \multirow[t]{3}{*}{ Edades } & $0-11$ meses & 50 & 24 & 48,0 & 26 & 8 & 30,8 \\
\hline & $12-23$ meses & 23 & 15 & 65,2 & 14 & 8 & 57,1 \\
\hline & 2 - 5 años & 15 & 11 & 73,3 & 10 & 7 & 70,0 \\
\hline \multirow{3}{*}{$\begin{array}{l}\text { Educación } \\
\text { materna }\end{array}$} & analfabeta & 8 & 4 & 50,0 & 5 & 2 & 40,0 \\
\hline & básica & 63 & 36 & 57,1 & 36 & 15 & 41,7 \\
\hline & media & 17 & 10 & 58,8 & 9 & 6 & $.66,7$ \\
\hline \multirow{2}{*}{$\begin{array}{l}\text { Estado } \\
\text { nutritivo }\end{array}$} & eutróficos & 62 & 33 & 53,2 & 31 & 15 & 48,4 \\
\hline & desnutridos & 26 & 17 & 65,4 & 19 & 8 & 42,1 \\
\hline \multirow{2}{*}{$\begin{array}{l}\text { Diarrea últimos } \\
\text { dos meses }\end{array}$} & sí n & 34 & 23 & 67,7 & 4 & 3 & 75,0 \\
\hline & no & 54 & 27 & 50,0 & 46 & 20 & 43,5 \\
\hline \multirow{2}{*}{$\begin{array}{l}\text { Antecedentes diarrea } \\
\text { grupo familiar }\end{array}$} & sí & 16 & 14 & 87,5 & 1 & 0 & 0,0 \\
\hline & no & 72 & 36 & 50,0 & 49 & 23 & 46,9 \\
\hline \multirow[t]{2}{*}{ Agua potable } & en casa & 54 & 30 & 55,6 & 38 & 15 & 39,5 \\
\hline & de acarreo & 34 & 20 & 58,8 & 12 & 8 & 66,7 \\
\hline \multirow{2}{*}{$\begin{array}{l}\text { Disposición de } \\
\text { excretas }\end{array}$} & adecuada & 40 & 22 & 55,0 & 24 & 8 & 33,3 \\
\hline & inadecuada & 48 & 28 & 58,3 & 26 & 15 & 57,7 \\
\hline \multirow[t]{2}{*}{ Vectores } & sí & 73 & 41 & 52,6 & 27 & 16 & 59,3 \\
\hline & no & 15 & 9 & 60,0 & 23 & 7 & 30,4 \\
\hline \multirow{2}{*}{$\begin{array}{l}\text { Personas por } \\
\text { pieza }\end{array}$} & $1-2$ & 64 & 38 & 59,4 & 41 & 18 & 43,9 \\
\hline & 3 y más & 24 & 12 & 50,0 & 9 & 5 & 55,6 \\
\hline \multirow{2}{*}{$\begin{array}{l}\text { Personas por } \\
\text { cama }\end{array}$} & 1 & 26 & 12 & 46,2 & 35 & 14 & 40,0 \\
\hline & 2 y más & 62 & 38 & 61,3 & 15 & 9 & 60,0 \\
\hline
\end{tabular}

En los niños sanos y enfermos que declararon síntomas sospechosos de enteroparasitosis se aisló parásitos en grado significativamente mayor que en los que no declararon.

En los niños sanos y enfermos, con alta promiscuidad, se tiende a aislar más frecuentemente los tres tipos de gérmenes.

Se aprecia un efecto más favorable del agregado de antibiótico, habitualmente cloramfenicol, sobre la evolución clínica que cuando se indica sólo dieta e hidratación.

Al relacionar las características del coprocultivo con el tratamiento se encontró, sin embargo, que del $84 \%$ de los casos que mejoraron con antibiótico-terapia, sólo en la mitad de ellos se aisló gérmenes susceptibles de ser afectados por los antibióticos en uso. El resto no presentó aislamiento de bacterias ni parásitos. Además no se concentró en este último grupo un número significativo de niños que hubieran recibido tratamiento antibiótico previamente a la toma de muestras.

Este hallazgo se ve corroborado por lo expuesto en la tabla 4 en que no se aprecia modificación de la mejoría según las características del coprocultivo. Finalmente cabe recordar el eventual influjo dispéptico que pueda tener el cuadro mórbido concomitante encontrado en un $40 \%$ de los enfermos.

Observamos que el grado de aislamiento de virus enteropatógenos es sensiblemente igual en los niños vacunados, tanto con diarrea como sanos.

Los niños vacunados más de 60 días antes de la diarrea y los no vacunados presentaron virus en las deposiciones con menos frecuencia que aquéllos con vacuna reciente.

Discusion. Se han descrito numerosas condiciones biológicas, sociales y económicas que determinan la incidencia de la diarrea $(1,2,3)$. No obstante, en el presente trabajo, al comparar dos grupos de niños menores de 6 años, uno con diarrea aguda $\mathrm{y}$ otro sano control, podemos ver que no existen diferencias significativas entre ellos cuando se consideran antecedentes tales como peso de nacimiento, nivel educacional 
CUADRO CLINICO Y EVOLUCION DE NIÑOS CON DIARREA, RELACIONADOS CON POSITIVIDAD DEL COPROCULTIVO

\begin{tabular}{|c|c|c|c|c|}
\hline \multirow[b]{2}{*}{ Características } & & \multirow{2}{*}{$\begin{array}{l}\text { Total } \\
\text { niños }\end{array}$} & \multicolumn{2}{|c|}{ Coprocultivo $(+)$} \\
\hline & & & $N^{a}$ & $\%$ \\
\hline \multirow{2}{*}{$\begin{array}{l}\text { Introducción de } \\
\text { nuevo alimento }\end{array}$} & sí & 18 & 11 & 61,1 \\
\hline & no & 70 & 39 & 55,6 \\
\hline \multirow{2}{*}{$\begin{array}{l}\text { Cuadro mórbido } \\
\text { concomitante }\end{array}$} & sí & 33 & 20 & 60,6 \\
\hline & no & 55 & 30 & 54,5 \\
\hline \multirow{3}{*}{$\begin{array}{l}\text { Horas de evolución } \\
\text { de la diarrea }\end{array}$} & -24 horas & 39 & 20 & 51,3 \\
\hline & $25 \cdot 72$ horas & 38 & 25 & 65,8 \\
\hline & 73 y más horas & 11 & 5 & 62,5 \\
\hline \multirow{2}{*}{$\begin{array}{l}\text { Tratamiento } \\
\text { previo }\end{array}$} & no & 37 & 20 & 54,1 \\
\hline & sí & 51 & 30 & 59,0 \\
\hline \multirow{4}{*}{$\begin{array}{l}\text { Características } \\
\text { de las } \\
\text { deposíciones }\end{array}$} & líquida & 23 & 13 & 56,5 \\
\hline & clisgregada & 65 & 37 & 56,9 \\
\hline & con mucus $y / o$ sangre & 35 & 17 & 48,6 \\
\hline & sin mucus ni sangre & 53 & 33 & 62,3 \\
\hline \multirow[t]{3}{*}{ Tipo de diarrea } & simple & 6 & 2 & 33,3 \\
\hline & sin deshidratación & 79 & 47 & 59,5 \\
\hline & con deshidratación & 3 & 1 & 33,3 \\
\hline \multirow[t]{2}{*}{ Temperatura } & febril & 49 & 27 & 55,0 \\
\hline & afebril & 39 & 23 & 59,0 \\
\hline \multirow[t]{2}{*}{ Vómitos } & sí & 33 & 15 & 45,5 \\
\hline & no & 55 & 35 & 63,6 \\
\hline Mejoría al & sí & 65 & 41 & 63,1 \\
\hline 4 día & no & 13 & 9 & 69,2 \\
\hline
\end{tabular}

T A B L A 10

TRATAMIENTO Y EVOLUCION CLINICA EN 78 NIÑOS CON DIARREA QUE VUELVEN A CONTROL

\begin{tabular}{lccc}
\hline \multicolumn{1}{c}{ Tratamiento indicado } & Total & \multicolumn{2}{c}{ Evolución al 4\% dia } \\
niños & \% mejoría & \% no mejoría \\
\hline dieta e hidratación & 6 & 50 & 50 \\
dieta, hidratación y antibiótico & 72 & 84 & 16 \\
\hline
\end{tabular}

T A B L A 11

AISLAMIENTO DE ENTEROVIRUS Y SU RELACION CON ANTECEDENTE DE VACUNA ANTIPOLIOMIELITICA ORAL

\begin{tabular}{|c|c|c|c|c|c|c|c|}
\hline \multirow[t]{2}{*}{$\begin{array}{l}\text { Antecedentes de } \\
\text { vacuna polio oral }\end{array}$} & & $\begin{array}{l}\text { GRUPO } \\
\text { Total } \\
\end{array}$ & \multicolumn{2}{|c|}{ DIARREA } & \multirow{2}{*}{$\frac{\text { Total }}{\text { niños }}$} & \multicolumn{2}{|c|}{$\begin{array}{l}\text { GRUPO SANO } \\
\text { con enterovuri }\end{array}$} \\
\hline & & niños & $N^{o}$ & $\%$ & & $N^{o}$ & $\%$ \\
\hline \multirow{2}{*}{ vacunados } & $(-60$ dias & 20 & 6 & 30,0 & 12 & 3 & 25,0 \\
\hline & $(+60$ días & 62 & 14 & 22,6 & 37 & 5 & 13,5 \\
\hline no vacunados & & 6 & 1 & 16,6 & 1 & 0 & 0,0 \\
\hline
\end{tabular}


de la madre, estado nutritivo previo, disponibilidad de agua potable, disposición de excretas y grado de hacinamiento.

En cambio, el grupo diarrea mostró en un grado significativamente mayor que el grupo sano, situaciones caracterizadas por diarrea aguda durante los dos meses anteriores, presencia de otro enfermo con diarrea en el hogar, presencia de vectores y alto grado de promiscuidad; situaciones interrelacionadas que conforman un hecho epidemiológico de alto interés. Debemos agregar que los niños en estas condiciones presentaron un nivel significativamente mayor de aislamiento de los tres tipos de microorganismos que los niños sanos. Ello indica la existencia de grupos familiares en donde la circulación y transmisión de gérmenes enteropatógenos entre sus componentes ocurriría con alta intensidad y frecuencia.

Esta situación coincide en parte con estudios que indican que el medio principal de propagación es el contacto directo y que los casos secundarios de un caso de diarrea en una familia tienen lugar preferentemente en los niños menores de 5 años $(2,4)$. La gran frecuencia de casos índices habitualmente encontrada entre los niños menores de 5 años, está indicando que la infección tiene su origen dentro de la familia más que en fuentes externas.

Se ha visto que aunque la desnutrición y la diarrea no están relacionadas estricta y directamente, ésta puede precipitar la desnutrición manifiesta cuando existe previamente un estado nutritivo precario. Igualmente, el niño mal nutrido parece más susceptible a las enfermedades diarreicas que el eutrófico. No obstante, los resultados de este trabajo no pueden ir en contra de tales aseveraciones, aun cuando los sanos desnutridos declaran episodios diarreicos previos menos frecuentemente que los con diarrea.

Las diferencias observadas en la prevalencia de desnutrición en niños enfermos y sanos en relación a los antecedentes ambientales, no fueron significativas. No obstante ello, ambos grupos tienen globalmente, los enfermos más acentuadamente y los sanos más atenuadamente, índices de desnutrición significativamente relacionados con los indices de malas condiciones de vida.

Las características del cuadro diarreico en esta ocasión, se resumen en débil influencia dietética como causa probable de la diarrea, enfermedad clínicamente afebril o subfebril, con 4-6 evacuaciones diarias sin caracteres disentéricos, predominantemente sin deshidratación y con escasos vómitos. Un factor importante en condicionar estas ca- racterísticas lo constituyó la consulta precoz. Además, es posible aseverar que la consulta precoz por diarrea aguda y la instauración de una terapia dietética adecuada, favorecen altamente una recuperación satisfactoria del cuadro clínico, evolución que pasaría a ser bastante independiente de las condiciones socio-ambientales y del estado nutritivo previo del enfermo.

Se pudo ver un aparente efecto importante en la evolución del cuadro clínico cuando se agregó antibiótico. Sin embargo, de su real efecto, la interpretación es difícil, ya que en la mitad de esos casos con buena evolución y con antibióticoterapia, no se aisló previamente gérmenes susceptibles de ser afectados por ella, además de las consideraciones respecto del cuadro mórbido concomitante que puedan caber.

La positividad de los coprocultivos fue de $57 \%$ y $46 \%$ para los enfermos y los sanos respectivamente, cifras que no muestran diferencia significativa. Globalmente en ellos las bacterias se aislaron en un $27,5 \%$, los virus en un $21 \%$ y los parásitos en un $27,7 \%$. El grado de positividad global del coprocultivo para sanos y enfermos, excepto contactos, fue de un $53 \%$.

En los enfermos se encontró una proporción similar en el aislamiento de bacterias, virus y parásitos como agente único: $12,5 \%$, $11,3 \%$ y $14,7 \%$ respectivamente.

Como agente infeccioso único, destaca un mayor aislamiento de virus en el grupo enfermo que en el grupo sano. Este hecho no se observó para bacterias ni parásitos. Además, es llamativa la alta proporción de resultados polimicrobianos, encontrándose proporciones semejantes de participación de virus, bacterias y parásitos en la composición de dichos resultados, tanto en enfermos como sanos.

Los contactos de niños con diarrea, casi todos entre 2 y 5 años de edad, muestran alto grado de contaminación, con un $80 \%$ de positividad del coprocultivo fundamentalmente a parásitos.

El grado de positividad global del coprocultivo y para los distintos gérmenes, encontrado en los niños con diarrea, es sensiblemente similar a valores encontrados por estudios tanto nacionales como extranjeros $(5,6,7,8,9,10,11)$.

El grado de aislamiento bacteriano, similar en sanos y enfermos, es levemente inferior o igual a los resultados obtenidos en otros estudios. En esta ocasión se aisló escherichia coli patógena en enfermos en un $25 \%$, en sanos en un $26 \%$ y en contactos en un $20 \%$. Aun con estos valores, el tipo 055 
se concentró significativamente más en el grupo con diarrea que en el resto.

El aislamiento de salmonellas y shigellas no presentó valor digno de destacar y fue inferior al encontrado en otras ocasiones en el país.

En cambio, el grado de aislamiento viral obtenido en sanos y enfermos (16\% y $23 \%$ respectivamente, es mayor que lo encontrado en ocasiones anteriores en Santiago (6). Las diferencias pueden atribuirse en parte, al mayor rango del huésped utilizado esta vez en el laboratorio. El mayor aislamiento de virus Echo en enfermos que en sanos, coincide con las tendencias universales que le atribuyen un rol significativo en la génesis de las diarreas.

El grado de aislamiento de parásitos en las sanos coincide con las cifras descritas en los últimos años para la población asintomática de la región central del país $(12,13)$. En ella se ha encontrado una prevalencia de giardia lamblia de $25 \%$ y $30 \%$ para niños sanos de 1-6 años y de 0-9 años respectivamente.

En esta ocasión el aislamiento de giardia lamblia fue de 20,30 y $53 \%$ en sanos, enfermos y contactos respectivamente. Es llamativa la proporción de contaminación en niños sanos contactos de enfermos, que es más alta que las cifras recién mencionadas para poblaciones infantiles algo comparables. Esto está de acuerdo con lo descrito en el sentido de que existen dos grupos de interés epidemiológico respecto de este parásito: un grupo portador asintomático formado por niños bien nutridos $\mathrm{y}$ adultos $\mathrm{y}$ un grupo sintomático que generalmente comprende niños desnutridos (14). En esta oportunidad no se consignó el estado nutritivo de los contactos; sin embargo, entre los niños enfermos la prevalencia de giardia lamblia fue significativamente mayor en los desnutridos que en los eutróficos.

De interés epidemiológico es el hallazgo de este grupo de contactos preescolares sanos con alta tasa de enteroparasitosis y su posible rol en la génesis de la diarrea aguda e nlos niños convivientes menores que ellos.

La alta prevalencia de giardia lamblia coincide con lo descrito para sectores urbanos de alta densidad de población y para pequeños grupos muy hacinados. En esta oportunidad se encontró que los niños enfermos con alto grado de promiscuidad presentaron enteroparásitos más frecuentemente que los enfermos sin promiscuidad. Ello refuerza lo planteado acerca del mayor o menor grado de contacto entre las personas en ex- plicar el menor o mayor riesgo de transmisibilidad.

No se encontró más giardia lamblia en los niños que acusaban episodios diarreicos a repetición en los dos meses anteriores que en el grupo contrario.

Indagar premeditadamente sobre síntomas sospechosos de enteroparasitosis, se ve reforzado por coincidir en alto grado con la positividad del examen cuando aquéllos eran positivos.

Los antecedentes epidemiológicos indican que el sindrome diarreico de naturaleza infecciosa está relacionado con gran variedad de gérmenes. Pero una proporción importante de las diarreas no tiene agente etiológico identificable con las técnicas habituales así como no todas son de origen infec. cioso.

Más aún, el hecho de aislar alguno de los tres tipos de microorganismos en un enfermo, no es razón suficiente para adjudicarle un valor etiológico ya que su participación última en general se presenta muy discutida. Esto es más crítico cuando en un mismo paciente con diarrea se aislan dos o más gérmenes simultáneamente.

A este respecto son de destacar los planteamientos hechos en el sentido de estudiar la acción patógena sinérgica que bacterias, virus y parásitos pudieran tener entre sí para desencadenar un cuadro diarreico (15).

La literatura muestra que se puede encontrar por lo menos un $10 \%$ de infección polimicrobiana en casos de diarreas infantiles. Es evidente la dificultad en interpretar estos resultados. Más aun cuando, como ahora, son bastante similares para los grupos enfermo y sano y cuando hay una relativa homogeneidad en la distribución de los gérmenes. Sin embargo, independientemente de aislamiento de germen único o varios y teniendo en cuenta las consideraciones que se exponen, podemos pensar que en esta ocasión la escherichia coli 055, algunas variedades de virus Echo y la giardia lamblia estarían jugando un rol importante en la diarrea del grupo estudiado.

La situación es de más difícil interpretación cuando se observan hallazgos microbiológicos cuantitativa y cualitativamente similares en individuos sanos. Este hecho ya ha sido descrito por diversos estudios epidemiológicos que muestran una elevada frecuencia de agentes microbianos patógenos conocidos en portadores sanos.

Debemos agregar que se encontró un rol aparentemente discutible del aislamiento de microorganismos en determinar la evolución del cuadro clínico, ya que con presencia o 
ausencia de ellos en las deposiciones el grado de mejoría fue similar.

Las interpretaciones etiopatogénicas sobre los gérmenes aislados requieren de estudios que demuestren su real rol etiológico. Esto se hace imperativo ya que una proporción importante de diarrea no muestra aislamiento ni mecanismos microbianos conocidos a que atribuirla.

Ante las recomendaciones para desarrollar medios de lucha biológica contra las infecciones entéricas por medio de microorganismos no patógenos que puedan competir con los patógenos, se pudo observar lo siguiente.

Al indagar el grado de aislamiento de enterovirus patógenos en los niños scgún si hubieran recibido recientemente o no la vacuna antipoliomielítica oral a modo de competidor, no se halló resultados como los encontrados en otras ocasiones (16).

Los niños con diarrea que habían recibido la vacuna Sabin dentro de los 60 días previos a la enfermedad, no mostraron una menor prevalencia de enterovirus patógenos como se postulaba. Cosa similar ocurrió en el grupo sano control.

\section{RESUMEN}

Durante el verano de 1973 en la ciudad de Santiago, se efectuó estudio clinico, microbiológico y de relaciones epidemiológicas de las diarreas agudas ambulatorias de corta evolución en niños menores de 6 años, comparándose con niños sanos y con convivientes contactos de los enfermos.

Se encontró un efecto positivo de la consulta precoz sobre la evolución del cuadro clínico.

Parte de los antecedentes ambientales no presentaron diferencias de interés entre sanos y enfermos. Se identificó sin embargo entre los enfermos, un grupo de interés epidemiológico caracterizado por alta promiscuidad, alta frecuencia de cuadros diarreicos en los meses anteriores, mayor incidencia de otros enfermos con diarrea aguda en el hogar y mayor grado de aislamiento de todo tipo de gérmenes entéricos. La mayor prevalencia de enteroparásitos se concentró en este grupo y sus convivientes sanos.

Tanto en sanos como enfermos la desnutrición estuvo relacionada con caracteristicas de deterioro ambiental. Pero este hallazgo no mostró diferencias significativas al comparar ambos grupos. No obstante, los enfermos desnutridos, en comparación con los sanos desnutridos, presentaron un ma- yor antecedente de episodios diarreicos previos y un mayor grado de aislamiento de enteroparásitos.

Se aisló algún germen enteropatógeno en el 57\% de los casos con diarrea. La positividad del coprocultivo fue similar en sanos $y$ enfermos pero mayor en los contactos $(57 \%$, $46 \%$ y 80\% respectivamente). Destaca un mayor aislamiento de virus en los enfermos $y$ de parásitos en enfermos y sus contactos. En forma especifica, en los enfermos se aisló significativamente más escherichia coli 055, virus Echo y giardia lamblia.

Se comenta las dificultades para atribuir a los gérmenes encontrados un rol etiológico en la diarrea. No obstante, se destacan como de interés el aparente poco influjo de las modificaciones dietéticas, los resultados polimicrobianos del coprocultivo y el mayor aislamiento de virus $y$ de parásitos en los enfermos.

Igualmente se hace notar la dificultad en interpretar el efecto terapéutico real del agregado de antibióticos en la evolución clinica del tipo de diarrea analizado en esta ocasión.

Se comparan con la información nacional e internacional, los resultados de aislamiento microbiano en las deposiciones.

No se observó un efecto competidor del virus polio, en el sentido de desplazar el prendimiento de los enterovirus patógenos.

\section{SUMMARY}

Clinical features, stools pathogenic agents and cpidemiological characteristics of infantil diarrhea was studied in Santiago during Summer 1973.

Stools exams for pathogenic viruses, bacteria and parasites were made in children with diarrhea, in healthy ones and in children contacts of the sick group. They all were aged 0 to 5 years.

Environmental, social and educational backgrounds showed no difference as compaired in healthy and sick children. However, among children whith diarrhea promiscuity, diarrhea episodes during two months before, other sick people with diarrhea at home and higher degres of all kind of pathogens isolation was highly frequent.

Malnutrition in healthy and sick children was found to be highly related to lower quality environmental characteristics.

Any pathogen was isolated in 57\% in patients and in $46 \%$ in healthy children. Viral and parasite agents were specifically more commonly isolated from patients and their contacts than from healthy ones. Echo virus and giardia lamblia are the most outstanding. Bacterial pathogens were isolated at a rather constant rate among all groups. 
Escherichia coli 055 was significantly more frequent in patients. ture.

Early consultation resulted in mild clinical pic-

Real antibiotic effect on clinical evolution is discussed.

No compctitive action of oral antipolio atennuated vaccine was found in avoiding viral pathogens to cause diarrhca.

\section{REFERENCIAS}

1.- Armijo, R.- Epidemiología de las Diarreas Agudas de la Infancia. Bol. Of. Sanit. Panam. 57: 444-453, 1964.

2.- Crónica de la OMS, Infecciones entéricas. 19: $3-6 ; 1965$.

3.- Informe del Seminario sobre Diarreas Infantiles. Of. San. Pan.: O. Regional de la OMS. Facultad de Medicina de la Universidad de Chile, Colegio Médico de Chile. Chile, noviembre 1956. (A mimeógrafo).

4.- OPS/OMS.- Estudios y estrategias necesarios para reducir la morbilidad y mortalidad por infecciones entéricas. Discusiones Técnicas, 1974.

5.- Lobos, H., Aguilar, C. y Romero, H.- Bacteriología de las diarreas agudas en el lactante hospitalizado. Pediatría 8: 280-293, 1965.

6.-Wu, E., Contreras, G., Ohlbaum, A., González, C. y Gilabert, B.- Estudio sobre la etiología viral de las diarreas agudas del lactante e influencia de la vacunación Sabin sobre la flora de enterovirus. Revista Chilena de Pediatría 42: 225-238, 1971.
7.- Ramos-Alvarez, M. y Sabin, A.- Enteropatogenic viruses and bacterias in diarrhea. J.A.M.A. 167: № 2, mayo 10, 1958.

8.- Ramos-Alvarez, M-Virus y Bacterias en la diarrea de niños. Bol. Hosp. Infantil de Mex. 19: $153,1962$.

9.- Garcés, C. y Prado, E.- Etiología de las diarreas del lactante, Rcv. Chilena de Ped. 16: $695,1945$.

10.- Prado, E.; Dussert, E. y González, C.- Bacteriología de las diarreas infantiles, Bol. Inst. Bacteriológico Chile, 9: 32, 1959.

11.- Dussert, E.- Enterobacteriaceae. Apartado Esc. Salubridad U. de Chile, Santiago, 1963.

12.- Neghme, A. y Silva, R.- Distribución y frecucncia de las enteroparasitosis en Chile. Rev. SNS, vol. 1, 1956.

13.- Ramirez, R, y cols.- Frecuencia en Chile de las infecciones humanas por protozoos y helmintos intestinales (1962-1972). Bol. Chil. Parasitología, 27: 117, 1972.

14.- Atias, A.- Aspectos patogénicos de la giardiasis, Bol. Chil. de Parasit. 23: 74-77, 1968.

15.- Cramblett, H.C. y Siewers, C.M.F.- The etiology of gastroenteritis in infants and children, with emphasis on the occurrence of simultaneous mixed viral-bacterial infections. Pediatrics 35: 885-898, 1965.

16.- Contreras, G.- Sabin's vaccine used for nonspecific prevention of infant diarrhea of viral etiology. Pan American Health Organization 8: 123-132, 1974. 